\title{
Prévalence et diversité des spores des champignons mycorhiziens arbusculaires en culture de riz sous les différents systèmes de culture de riz dans cinq zones agro-écologiques au Togo
}

\author{
Gnamkoulamba Atama ${ }^{1,2}$, Tounou Agbeko Kodjo ${ }^{*}$, Tchabi Atti ${ }^{3}$, Agboka Komi1 ${ }^{1}$ Adjévi Anani Kossi \\ Mawuko', Batawila Komla ${ }^{4}$ \\ ${ }^{1}$ Ecole supérieure d'agronomie, université de Lomé, Laboratoire de Recherche sur les Agroressources et la Santé \\ Environnementale 01 BP 1515 Lomé 1-Togo, \\ ${ }^{2}$ Institut National de Formation Agricole (INFA) Tové, Ministère de l'Agriculture d'Élevage et de l'Hydraulique BP 401 \\ Kpalimé-Togo, \\ ${ }^{3}$ Université de Kara, Institut des Métier Agricoles BP : 43 Kara-Togo, ${ }^{4}$ Faculté des Sciences, Université de Lomé, \\ Laboratoire de Botanique et d'écologie Végétale 01 BP : 1515 Lomé 1-Togo
}

Original submitted in on $5^{\text {th }}$ June 2018. Published online at www.m.elewa.org on $30^{\text {th }}$ June 2018 https://dx.doi.org/10.4314/jab.v126i1.3

\section{RÉSUMÉ}

Objectif : La présente étude vise à évaluer la diversité et la prévalence des champignons mycorhiziens arbusculaires (CMA) sous différents systèmes rizicoles dans les différentes zones agroécologiques du Togo.

Méthodologie et résultats : Les substrats, constitués d'échantillons de sol prélevés dans les systèmes de riziculture des différentes zones agroécologiques, ont servi à piéger en pots les spores de CMA sur le riz, Oriza sativa L. (Poales), variété IR841 en utilisant le sorgho, Sorghum sudanense (Piper) Stapf comme plante piège de référence. La culture a été maintenue pendant une période de 12 mois en serre après laquelle les densités et la diversité des spores ont été évaluées. Les résultats ont montré une grande diversité des spores identifiées selon les systèmes de culture. Un total de 25 espèces appartenant principalement à sept genres (Acaulospora, Claroideoglomus, Entrophospora, Funneliformis, Gigaspora, Glomus et Rhizoglomus), ont été identifiés en utilisant les deux plantes pièges. Le niveau de sporulation a été plus élevé sur le sorgho que sur le riz. Les genres les plus fréquemment sporulées sont Rhizoglomus, Glomus et de Acaulospora, Claroideoglomus alors que le genre Gigaspora a été le moins fréquent. La densité des spores est plus élevée sur du sorgho que sur le riz. Les zones agroécologiques n'ont eu aucun effet sur la diversité et la densité des spores. Ces dernières ont été cependant influencées par les systèmes de culture de riz, avec la plus grande diversité et les plus fortes sporulations obtenues dans le système de riziculture de bas-fonds et les plus faibles dans le système culture de riz inondé.

Conclusion et application des résultats : La présente étude a identifié une grande diversité de champignons MA associés au riz dans les différents systèmes rizicoles au Togo, et dont certaines souches, connues pour leur utilisation en agriculture, pourront être utilisées comme biofertilisants pour une production durable du riz au Togo.

Mots clés : Ecologie rizicole, taux de mycorhization, spores, plantes pièges, Togo. 
Prevalence and diversity of spores of arbuscular mycorrhizal fungi in rice cultivation under different rice cropping systems in five agro-ecological zones in Togo

\begin{abstract}
Objective : The present study aims to evaluate the diversity and prevalence of arbuscular mycorrhizal fungi (AMF) under different rice cropping systems in the different agroecological zones of Togo.

Methodology and results : The substrates, consisting of soil samples taken from the rice cropping systems of the different agroecological zones, were used to trap the spores of AMF on rice, Oriza sativa L. (Poales) variety IR841, using sorghum, Sorghum sudanense (Piper) Stapf as a reference trap plant. The culture was maintained for a 12-month period in greenhouse after which spore densities and diversity were assessed. The results showed a great diversity of spores identified according to the culture systems. A total of 25 species belonging to seven genera (Acaulospora, Claroideoglomus, Entrophospora, Funneliformis, Gigaspora, Glomus and Rhizoglomus), were identified using both trap plants. The level of sporulation was higher on sorghum than on rice. The most frequently sporulated genera are Rhizoglomus, Glomus, Acaulospora and Claroideoglomus, while the genus Gigaspora was the least common. Spore density was higher on sorghum than on rice. Agroecological zones had no effect on spore diversity and density. Spore diversity and density, however, have been influenced by rice cropping systems, with the greatest diversity and sporulation obtained in the lowland rice cropping system and the lowest in the flooded rice cropping system.

Conclusion and application of the findings: The present study has identified a large diversity of AMF associated with rice in the various rice systems in Togo, some of which, known for their use in agriculture, could be used as biofertilizers for sustainable production of rice in Togo.
\end{abstract}

Keywords: Rice ecology, mycorrhization rates, spores, trap plants, Togo.

\section{INTRODUCTION}

Les champignons mycorhiziens arbusculaires (CMA) sont présents dans la plupart des écosystèmes et constituent une composante importante de la microflore des sols tropicaux (Cardoso et Kuyper, 2006; Tchabi et al., 2008). Cependant, la connaissance et la compréhension de la structure et des dynamiques au sein des communautés CMA sont une condition nécessaire pour la détermination des effets bénéfiques spécifiques des CMA, en particulier dans les agroécosystèmes tropicaux à faibles intrants dans lesquels la gestion durable des ressources nutritives du sol généralement faibles doit prendre en compte des avantages des micro-organismes indigènes (Cardoso et Kuyper 2006; Lovera et Cuenca, 2007). Des progrès dans le domaine de l'identification des CMA et en particulier le développement rapide d'outils moléculaires pour l'identification (Redecker, 2000), ont régulièrement augmenté le nombre d'études sur la diversité des CMA (Gai et al., 2006 ; Wu et al., 2007). De telles études ont permis une meilleure compréhension du lien entre les communautés des CMA et divers paramètres, tels que les systèmes de culture et l'intensification des pratiques culturales (Jansa et al., 2002 ; Oehl et al., 2004), les types de sol (Lekberg et al., 2007), la profondeur du sol (Oehl et al., 2005). Si de nombreux travaux sur la diversité des CMA ont été menées dans des pays asiatiques et occidentaux (Oehl et al., 2005 ; Wu et al., 2007), à ce jour, les études sur la diversité et l'identification des CMA dans les écosystèmes africains sont relativement limitées (Lekberg et al., 2007 ; Mathimaran et al., 2007), avec une rareté particulière en Afrique en Ouest tropicale (Lovelock et Ewel 2005 ; Tchabi et al., 2008). En Afrique de I'Ouest, en particulier au Togo, l'impact des pratiques agricoles sur la composition et la diversité des CMA reste largement méconnu. Au Togo, le riz est généralement cultivé par les petits producteurs dans un système de monoculture ou culture mixte pendant la saison des pluies, avec la rotation des cultures d'une saison à l'autre. Sa culture est assurée par un faible niveau d'intrants 


\section{Gnamkoulamba et al, J. Appl. Biosci. 2018 Prévalence et diversité des spores des champignons}

mycorhiziens arbusculaires en culture de riz sous les différents systèmes de culture de riz au Togo.

externes et est destinée à répondre aux besoins de consommation locale. Les sols au Togo comme dans la plus part des pays de l'Afrique de l'Ouest, sont principalement de type ferralitique et se caractérisent par une faible disponibilité des nutriments et une dégradation importante due à la perte physique et à la lixiviation des minéraux, en particulier le phosphore disponible, en raison des fortes pluies, entrainant une chute rapide des récoltes (Defoer et Scoones 2001). L'infertilité des sols et le déclin subséquent du rendement sont également en partie liés à la réduction de la prévalence et à la perte de la diversité de la microflore et de la microfaune telluriques, comme les CMA bénéfiques, due à de mauvaises pratiques agricoles (Johnson et al., 1992). L'utilisation des engrais minéraux dans les rizières conduit à la pollution de l'environnement par émission de méthane (IRRI, 2011). SelonFuehrer (2011), l'émission de méthane d'origine anthropique serait en grande partie liée aux

\section{MATÉRIELS ET MÉTHODES}

Cadre de l'étude : L'étude a été conduite dans les différentes zones agroécologiques du Togo, un pays de l'Afrique de l'Ouest situé entre le $6^{\circ} 06 \mathrm{~N}$ et $11^{\circ} 08^{\circ} \mathrm{N}$ de latitude nord et $0^{\circ} 09 \mathrm{~W}$ et $1^{\circ} 49$ de longitude Ouest, abritant 6191155 habitants dont plus de 60\% (62,3\%) vie en milieu rural (Figure 1). Sur le plan climatique, deux zones se distinguent par rapport à la latitude $8^{\circ} \mathrm{N}$. Au nord un climat de type monomodal soudanien avec une saison des pluies et une saison sèche. Au sud, le climat est de type guinéen caractérisé par deux saisons sèches et deux saisons pluvieuses : une grande saison des pluies de mars à juillet, une petite saison sèche d'août à mi-septembre, une petite saison des pluies de mi-septembre à novembre suivi d'une grande saison sèche de décembre à février. La végétation est dominée par les Combretaceae dans les plaines du nord (zone agroécologique 1), Isoberlinia spp. (Caesalpiniacea) dans les montagnes du nord (zone agroécologique 2). Dans les plaines du centre (zone agroécologique 3), Anogeisus leiocarpa (Combretaceae) et Pterocarpus erinaceus (Fabaceae) sont les plus représentés (Adjonou et al., 2010). La flore est beaucoup diversifiée avec Celtis mildbreadii Eng (Cannabaceae), Terminalia superba Eng \& Diels (Combretaceae) et Ricinodendron heudelotii (Baill.) (Euphorbiacea) dans la zone méridionale des monts cultures de riz. Parmi les mesures d'atténuation proposées pour réduire l'émission des gaz à effets de serre dans les rizières, la gestion de l'eau et l'utilisation de fertilisants organiques ont été les plus prometteuses. Ces deux techniques permettent en effet l'installation d'une flore de champignons dont les champignons mycorhiziens qui favorisent la formation de glomaline qui conduit à la formation des agrégats du sol où le carbone résiste mieux à la dégradation (Rillig et al.,2003). La présente étude a investigué la diversité et la prévalence des champignons mycorhiziens arbusculaires dans les différents systèmes de culture du riz dans les cinq zones écologiques du Togo : la zone agroécologique 1 (plaines du nord) ; la zone agroécologique 2 (montagnes du nord); la zone agroécologique 3 (plaines du centre); la zone agroécologique 4 (zone méridionale des monts Togo) et la zone agroécologique 5 (zone des plaines côtières du sud).

Togo (zone agroécologique 4) alors que dans les plaines côtières du sud (zone agroécologique 5) les mangroves sont particulièrement plus présents (Adjonou et al., 2010). Les plaines du nord sont dominés par les sols ferrugineux tropicaux lessivés en surface, argileux, concrétionnés ou indurés (à cuirasse ou carapace) dans l'horizon de profondeur et les sols hydromorphes à engorgement d'eau. Au niveau des montagnes du nord, on rencontre des sols ferrugineux tropicaux lessivés, concrétionnés ou indurés (à cuirasse ou carapace) et les sols peu évolués d'érosion, squelettique et caillouteux. Les plaines du centre sont dominées par les sols ferrugineux tropicaux lessivés, concrétionnés ou indurés (à cuirasse ou carapace). Dans les zones méridionales des monts Togo, les sols sont de type ferrallitique et peu évolués d'érosion. Dans les plaines côtières sont dominés par les sols ferrallitiques (terre de barre), les sols hydromorphes (sol à engorgement d'eau de couleur grise avec des taches rouille, ocre, verdâtre) à caractère vertique et les vertisols (sol lourd argileux très plastiques et adhérents en saison pluvieuse et présentant des fentes de retrait en saison sèche). En général le $\mathrm{pH}$ de tous les sols varie de 5,5 à 7 alors que le taux de matière organique est compris entre 1 et $3 \%$ selon la végétation (Lamouroux, 1960). 


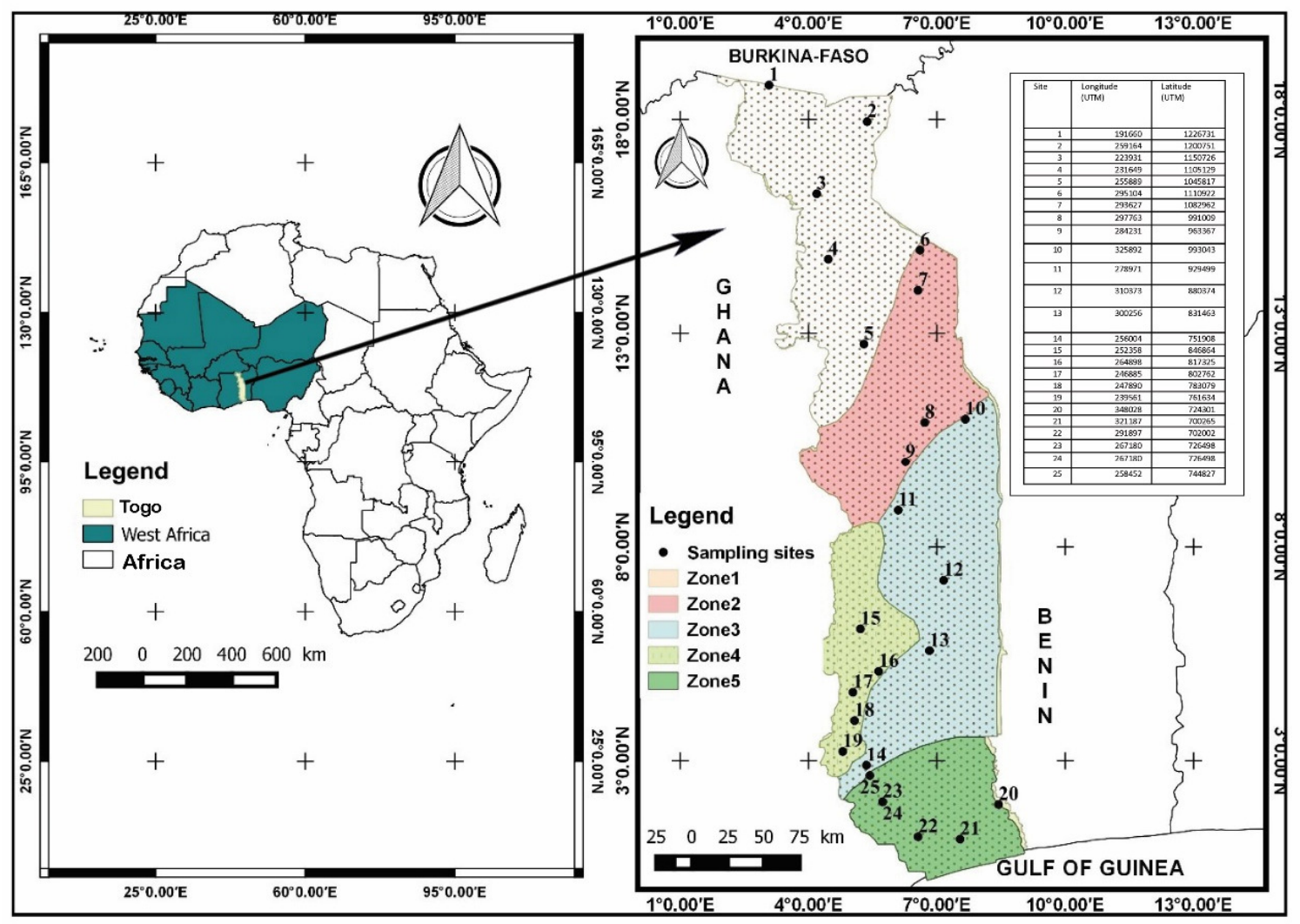

Figure 1 : Localisation des sites de prélèvement des échantillons

Prélèvement du sol et des racines : Dans chaque zone écologique, huit (8) parcelles de riz ont été choisies au hasard. Sur chaque parcelle, 4 échantillons de $300 \mathrm{~g}$ chacun sont prélevés à une profondeur de 10$20 \mathrm{~cm}$ à l'aide d'une sonde de $25 \mathrm{~cm}^{3}$ en suivant les diagonales de la parcelle. A chaque prélèvement, les coordonnées GPS ont été notées ainsi que le type de culture du riz. Avant chaque prélèvement, la sonde est lavée à l'eau afin d'éviter toute contamination. Les échantillons prélevés dans des sachets plastiques sont convoyés au Laboratoire des sols et Végétaux (LSV) de l'École Supérieure d'Agronomique de l'Université de Lomé (ESA-UL), séchés à l'air ambiant pendant $72 \mathrm{~h}$ et conservés au réfrigérateur à $4^{\circ} \mathrm{C}$ pour inoculum ultérieure.

Le piégeage des Champignons mycorhiziens arbusculaires : Le piégeage des spores de CMA a été fait en serre sur les plants de riz, Oriza sativa variété $\mathrm{L}$ (Poales) IR84. Le sorgho, Sorghum sudanense a été utilisé comme plante piège de référence. Dans chaque zone écologique, quatre pots de 5 litres de volume ont été utilisés par système de riziculture, un pot par répétition de chaque système de riziculture selon Oehl et al. (2003). Pour chaque pot, $4 \mathrm{~kg}$ de substrat composé d'un mélange stérilisé 3:1 (masse/masse) de sol arable et le sol de rivière stérilisés à la chaleur à $100^{\circ} \mathrm{C}$ pendant $1 \mathrm{~h}$, ont été utilisés. $3 \mathrm{~kg}$ du substrat composite sont introduits dans un premier temps dans chaque pot. Sur le substrat composite, trois lignes de semis sont d'abord couvertes de $180 \mathrm{~g}$ d'inoculum de sol répartis équitablement sur les trois lignes. Trois grains de chaque plante piège, stérilisés à l'alcool 90 degrés pendant $1 \mathrm{mn}$ et rincées avec l'eau distillée, sont ensuite semées par pot le long des trois lignes de l'inoculum. Chaque pot ainsi ensemencé est ensuite recouvert de $1 \mathrm{~kg}$ de substrat composite restant. Pour chaque plante piège, un total de 64 pots ont été mis en place, dont quatre pots de contrôle non mycorhiziens. Les cultures pièges ont été maintenues dans une serre à l'université de Lomé pendant 12 mois, temps nécessaire à la sporulation de tous les types de mycorhize. Les plants germés ont été quotidiennement arrosés durant toute la phase de développement. Un ré-semis a été effectué à chaque fois que la plante arrivait à sénescence. Les pots de piégeage ont été maintenus dans la serre puis arrosés pendant 12 mois. Échantillonnage des cultures pièges : Après les 12 mois de piégeage en serre, deux échantillons de 15 
$\mathrm{cm}^{3}$ de sol ont été prélevés par pot à $10-15 \mathrm{~cm}$ de profondeur pour des tests d'isolement et l'identification des spores de CMA.

Isolement et identification morphologique des champignons mycorhiziens : Les spores de CMA ont été isolées à partir de $30 \mathrm{~cm}^{3}$ de sol prélevés dans chaque pot qui ont été mis en suspension dans l'eau en suivant la méthode de Oehl et al. (2003). Les spores ont été extraites par tamisage humide à travers des séries de tamis emboîtés (de 1000, 125, 80 et 32 $\mu \mathrm{m})$ suivies par une centrifugation en gradient de densité. A partir des tamis de $1000 \mu \mathrm{m}$, aucun spore ou sporocarpes n'a été obtenus, et seuls les contenus des tamis de 125,80 et $35 \mu \mathrm{m}$ ont été versés dans des flacons de $50 \mathrm{ml}$ et centrifugés dans un gradient de $70 \%$ de solution de saccharose (Oehl et al., 2003). Après centrifugation à $2000 \mathrm{tr} / \mathrm{min}$ pendant $5 \mathrm{~min}$, les spores, les amas de spores et les sporocarpes obtenus dans chaque pot ont été transférés dans des boîtes de Pétri et comptés à l'aide d'une loupe binoculaire ( $G \mathrm{X}$ 40). Pour l'identification microscopique, des spores saines ont été montés sur des lames de verre et colorées avec du polyvinyle lactique acide glycérol (PVLG) mélangé avec le réactif de Melzer (1: $1 \mathrm{vol} /$ vol, Brundrett et al., 1994). L'examen des spores a été fait sous microscope binoculaire $(G \times 400)$ et

\section{RÉSULTATS}

Mycorhization des plants pièges en serre : Aucune trace de champignons mycorhiziens n'a été observée dans les pots témoin. Cependant, l'examen des plans pièges semés sur les substrats de sol des sites de prélèvement, ont révélé des niveaux élevés de mycorhization des plants pouvant atteindre sur le sorgho des niveaux de $88,52 \pm 2,75 ; 88,87 \pm 2,91$ et $91,63 \pm 2,75 \%$, contre $57,4 \pm 3,48 ; 60,02 \pm 4,62$; et $70,40 \pm 2,49 \%$ sur le riz, respectivement pour les échantillons de sol de riz inondé, riz de plateau et riz de bas-fond. Indépendamment des zones agroécologiques, les taux de sporulation des CMA l'identification a été faite sur la base de manuel de description et d'identisation de Schenck et Pérez (1990).

Analyses statistiques : La densité des spores (= abondance des spores) dans un échantillon de sol a été exprimée en nombre de spores de CMA par gramme de sol. Pour la détermination des taux de mycorhization des CMA dans chaque système rizicole, les échantillons de sol provenant des différentes zones agroécologiques ont été combinés suivant les types de rizicultures. Les interactions système rizicole et zones agroécologiques n'étant pas significatives, la richesse spécifique des CMA par zone écologique a été déterminée en cumulant les moyennes des systèmes rizicoles. De même la richesse spécifique des CMA par système rizicole a été déterminée en cumulant les moyennes des zones agroécologiques. La densité des spores et la richesse en espèces ont été analysées à l'aide de la procédure PROC d'analyse de la variance (ANOVA) de SAS version 9.1. Les différences significatives entre les sites de terrain ont été testées en utilisant la différence la moins significative de Fisher (LSD) à $P<0,05$. Avant l'analyse, les données sur la densité des spores étaient transformées $\log (x+1)$ pour normaliser les données.

prélevés sur les sites de rizicoles, était généralement plus élevés dans les pots plantés au sorgho comparé aux pots plantés au riz $(P<0,05)$. Sur le sorgho, le système de riziculture n'a eu aucun effet significatif sur le taux de mycorhization des plants $(P>0.05)$. Par contre sur le riz, les taux de mycorhization des plants sur les échantillons prélevés des rizières des sols de basfond étaient significativement plus élevés que ceux provenant des sites de riz des plateaux et du riz inondé, les deux derniers ayant montré un niveau similaire de mycorhization (Figure 2). 


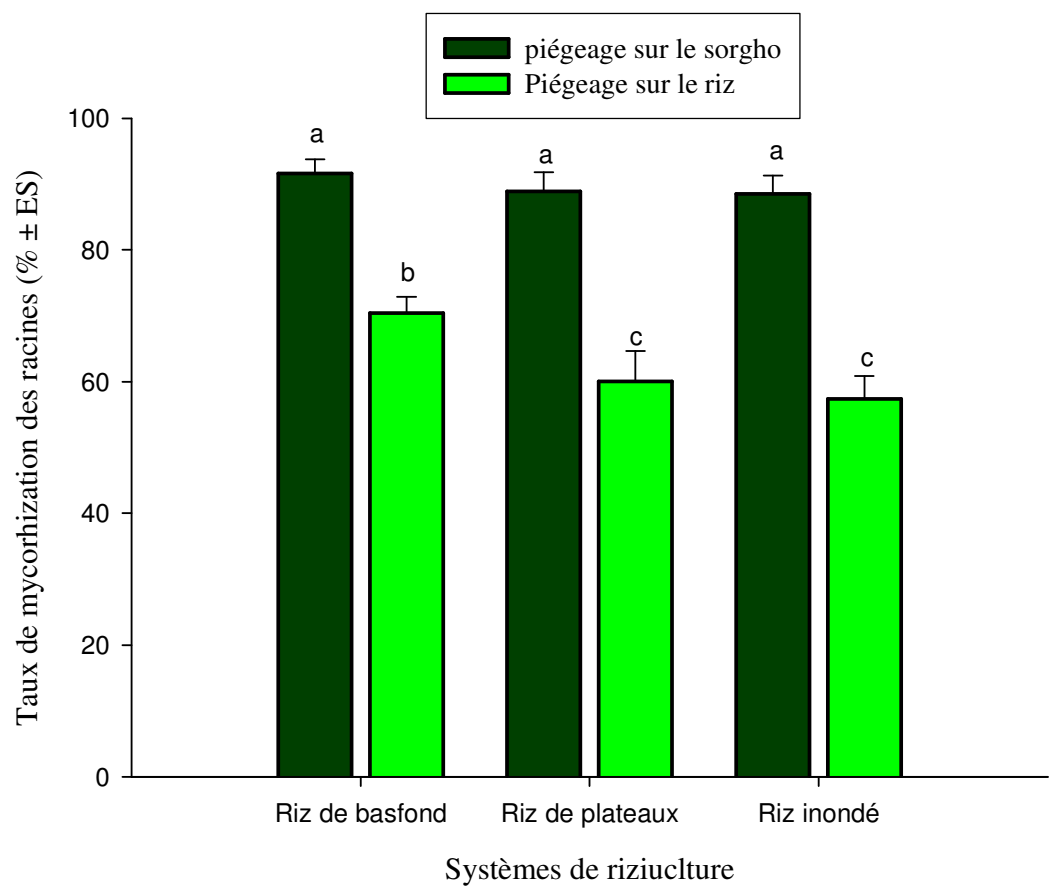

Figure 2. Taux de mycorhization en serre des plants pièges semés sur les échantillons de sol prélevés dans les différents systèmes de rizicultures.

Pour chaque système rizicole, les données des zones écologiques ont été cumulées. Les différences significatives entre les systèmes de culture sont indiquées par différentes lettres (test de StudentNewman-Keuls au seuil de 5\%).

Diversité spécifique des CMA selon les zones écologiques : Un total de 25 spécimens appartenant à sept genres (Acaulospora, Claroideoglomus, Entrophospora, Funneliformis, Gigaspora, Glomus et Rhizoglomus) de mycorhizes a été identifié. Le genre Rhizoglomus a été le plus représenté avec six espèces suivi des genres Glomus et Acaulospora avec cinq espèces chacun, du genre Claroideoglomus avec quatre espèces et des genres Entrophospora et
Funneliformis avec deux espèces chacun (Tableau 1). La richesse spécifique des CMA dans les différentes rizières explorées est restée presque identique dans les cinq zones agroécologiques, variant entre 19 spécimens dans la zone 2 et 25 dans la zone 5 . A l'exception de Acaulospora morrowiae, Acaulospora sp. 1, Acaulospora sp 2, Claroideoglomus sp. 1, Claroideoglomus sp2, Glomus brow, Glomus microcarpum, Glomus yelow sp., Rhizoglomus sp. 2, Rhizoglomus fasculatum et Gigaspora sp., toutes les autres espèces ont été retrouvées dans les cinq zones écologiques. Le genre Gigaspora particulièrement n'a été extrait que des échantillons provenant des Zones 1 et 5 .

Tableau 1 : Richesse spécifique des champignons mycorhiziens collectés dans les rizières des différentes zones agroécologiques tout système de riziculture confondu du Togo et piégé en serre sur le sorgho et le riz

\begin{tabular}{|c|c|c|c|c|c|}
\hline Espèces de CMA* & Zone $1^{\text {f }}$ & Zone 2 & Zone 3 & Zone 4 & Zone 5 \\
\hline Acaulospora morrowiae & $\mathrm{x}$ & - & $\mathrm{x}$ & $x$ & $x$ \\
\hline Acaulospora scorbiculata & $x$ & $x$ & $x$ & $x$ & $x$ \\
\hline Acaulospora spinosa & $x$ & $x$ & $x$ & $x$ & $x$ \\
\hline Acaulospora sp. 1 & - & $x$ & $x$ & $x$ & $x$ \\
\hline Acaulospora sp. 2 & - & $x$ & $x$ & $x$ & $x$ \\
\hline Claroideoglomus clariodeum & $x$ & $x$ & $x$ & $\mathrm{x}$ & $x$ \\
\hline Claroideoglomus etunicatum & $x$ & $x$ & $x$ & $x$ & $x$ \\
\hline Claroideoglomus sp. 1 & - & $x$ & $x$ & $x$ & $x$ \\
\hline Claroideoglomus sp. 2 & $x$ & - & $x$ & $x$ & $x$ \\
\hline
\end{tabular}


Gnamkoulamba et al, J. Appl. Biosci. 2018 Prévalence et diversité des spores des champignons mycorhiziens arbusculaires en culture de riz sous les différents systèmes de culture de riz au Togo.

\begin{tabular}{|c|c|c|c|c|c|}
\hline Espèces de CMA ${ }^{*}$ & Zone $1^{£}$ & Zone 2 & Zone 3 & Zone 4 & Zone 5 \\
\hline Entrophospora colombiana & $x$ & $x$ & $x$ & $x$ & $x$ \\
\hline Entrophospora infrequens & $x$ & $x$ & $x$ & $x$ & $x$ \\
\hline Funneliformis mosseae & $x$ & $x$ & $x$ & $x$ & $x$ \\
\hline Funneliformis sp. & $x$ & $x$ & $x$ & $x$ & $x$ \\
\hline Gigaspora sp. & $x$ & - & - & - & $x$ \\
\hline Glomus brow & - & - & $x$ & $x$ & $x$ \\
\hline Glomus macrocarpum & $x$ & $x$ & $x$ & $x$ & $x$ \\
\hline Glomus microcarpum & $x$ & $x$ & - & $x$ & $x$ \\
\hline Glomus thin sp. & $x$ & $x$ & $x$ & $x$ & $x$ \\
\hline Glomus yelow sp. & $x$ & - & $x$ & $x$ & $x$ \\
\hline Rhizoglomus sp. 2 & $x$ & - & $x$ & $x$ & $x$ \\
\hline Rhizoglomus aggregatum & $x$ & $x$ & $x$ & $x$ & $x$ \\
\hline Rhizoglomus fasculatum & - & $x$ & - & $x$ & $x$ \\
\hline Rhizoglomus intraradices & $x$ & $x$ & $x$ & $x$ & $x$ \\
\hline Rhizoglomus irregulare & $x$ & $x$ & $x$ & $x$ & $x$ \\
\hline Rhizoglomus sp. 1 & $x$ & $x$ & $x$ & $x$ & $x$ \\
\hline Nombre d'espèces & 20 & 19 & 22 & 24 & 25 \\
\hline Nombre total d'espèces & 25 & & & & \\
\hline
\end{tabular}

"Les données présentées sont des données cumulées des trois systèmes de riziculture : Riz de basfond, riz des plateaux et riz inondé. Ezone 1 : plaines du nord; zone 2 : montagnes du nord; zone $3:$ plaines du centre; zone $4:$ zone méridionale des monts Togo ; zone 5 : zone des plaines côtières du sud. $x$ = présence ; - = absence

Richesse spécifique des CMA en rapport avec les systèmes de culture de riz : La richesse en espèces de champignons mycorhiziens arbusculaires était généralement plus élevée $(P<0,05)$ dans les basfonds que dans les deux autres systèmes de culture (Tableau 2). Toutes les 25 espèces étaient présentes dans les bas-fonds contre 16 et 20 respectivement dans les systèmes de riz de plateau et de sol inondé (Tableau 2). Des 25 espèces, les spores de treize espèces (Acaulospora morrowiae, Acaulospora sp. 2, Claroideoglomus etunicatum, Entrophospora
Colombiana, $E$. infrequens, Funneliformis sp. G. macrocarpum, G. microcarpum, G. thin sp., Glomus yelow sp., Rhizoglomus sp. 2, Rhizoglomus aggregatum et Rhizoglomus sp. 1) ont été retrouvées dans les trois systèmes de riziculture (Tableau 2). Les espèces Claroideoglomus sp. 2 et Glomus brow n'ont été détectées que dans les bas-fonds. Les systèmes de riziculture a affecté négativement la richesse spécifique des CMA avec le plus grand nombre d'espèces obtenu dans les bas-fonds (25) suivis du riz inondé (20) et de riz des plateaux (16). 
Tableau 2. Espèces de champignons mycorhiziens arbusculaires détectées sous divers systèmes rizicoles dans les différentes zones agroécologiques du Togo.

\begin{tabular}{|c|c|c|c|}
\hline Espèces de CMA* & Riz de bas-fonds & Riz de plateau & Riz inondé \\
\hline Acaulospora morrowiae & $\mathrm{x}$ & $x$ & $\mathrm{x}$ \\
\hline A. scorbiculata & $x$ & - & $\mathrm{x}$ \\
\hline A. spinosa & $\mathrm{x}$ & - & $\mathrm{x}$ \\
\hline Acaulospora sp. 1 & $\mathrm{x}$ & $\mathrm{x}$ & - \\
\hline Acaulospora sp. 2 & $\mathrm{x}$ & $x$ & $\mathrm{x}$ \\
\hline Claroideoglomus clariodeum & $\mathrm{x}$ & - & $\mathrm{x}$ \\
\hline C. etunicatum & $\mathrm{x}$ & $\mathrm{x}$ & $\mathrm{x}$ \\
\hline Claroideoglomus sp. 1 & $\mathrm{x}$ & $\mathrm{x}$ & - \\
\hline Claroideoglomus sp. 2 & $\mathrm{x}$ & - & - \\
\hline Entrophospora colombiana & $x$ & $\mathrm{x}$ & $\mathrm{x}$ \\
\hline E. infrequens & $\mathrm{x}$ & $\mathrm{x}$ & $\mathrm{x}$ \\
\hline Funneliformis mosseae & $\mathrm{x}$ & - & $\mathrm{x}$ \\
\hline Funneliformis sp. & $x$ & $x$ & $x$ \\
\hline Gigaspora sp. & $\mathrm{x}$ & - & $\mathrm{x}$ \\
\hline Glomus brow & $\mathrm{x}$ & - & - \\
\hline G. macrocarpum & $\mathrm{x}$ & $x$ & $\mathrm{x}$ \\
\hline G. microcarpum & $\mathrm{x}$ & $\mathrm{x}$ & $\mathrm{x}$ \\
\hline G. thin sp. & $\mathrm{x}$ & $\mathrm{x}$ & $\mathrm{x}$ \\
\hline Glomus yelow sp. & $\mathrm{x}$ & $\mathrm{x}$ & $\mathrm{x}$ \\
\hline Rhizoglomus sp.2 & $\mathrm{x}$ & $\mathrm{x}$ & $\mathrm{x}$ \\
\hline Rhizoglomus aggregatum & $\mathrm{x}$ & $\mathrm{x}$ & $\mathrm{x}$ \\
\hline R. fasculatum & $\mathrm{x}$ & $\mathrm{x}$ & - \\
\hline R. intraradices & $\mathrm{x}$ & - & $\mathrm{x}$ \\
\hline R. irregulare & $x$ & - & $x$ \\
\hline Rhizoglomus sp. 1 & $\mathrm{x}$ & $\mathrm{x}$ & $\mathrm{x}$ \\
\hline Nombre d'espèces & 25 & 16 & 20 \\
\hline
\end{tabular}

Nombre total d'espèces 25

*Les données présentées sont des données cumulées des cinq zones agro-écologiques : Plaines du nord, Montagnes du nord, Plaines du centre, Zone méridionale des monts Togo et Plaines côtières du sud. $x=$ présence ; - = absence

Densité des CMA en rapport avec les systèmes de culture de riz et les cultures pièges : Après les 12 mois de piégeage, aucune trace de champignons mycorhiziens n'a été observée dans les pots témoin. Dans les traitements avec les substrats prélevés du champ par contre, les CMA ont sporulé, avec les 25 espèces identifiés sur le sorgho et 24 sur le riz. Seul Gigaspora sp. n'a été observé sporuler sur le riz. La sporulation des CMA était très variable selon les espèces, les systèmes de riziculture et les plantes pièges (Figures 3 à 8 ). Les plus fortes densités des CMA ont été obtenues sur le sorgho comparé au riz (Figures 3, 4, 5 6, 7 \& 8). Indépendamment des zones agroécologiques, la densité des spores de CMA était généralement plus élevée sur les échantillons de sol prélevés dans les bas-fonds comparés à ceux provenant des écosystèmes de riz de plateau et des sols inondés (Figures 3 à 8). Les espèces de champignons MA provenant des systèmes de riziculture de basfond ont montré les niveaux de sporulation les plus élevée pouvant dépasser sur le sorgho les 100 spores pour huit espèces de CMA (Figure 3). Un niveau maximum de 410,25 \pm 4,91 spores a été atteint pour Claroideoglomus etunicatum. Outre $C$. etunicatum, $R$. aggregatum, $E$. infrequens, Glomus thin sp., G. macrocarpum, F. mosseae, $R$. irregulare et $A$. morrowiae, ont atteint sur le sorgho des niveaux de densités respectivement de $350,25 \pm 5,44$, $239,5 \pm 3,65$ et $160,25 \pm 4,40 ; 130,25 \pm 2,70$; $110,75 \pm 2,81 ; 109,75 \pm 3,66$ et $100,25 \pm 6,36$ spores par $100 \mathrm{ml}$ de sol (Figure 3). Les espèces comme Claroideoglomus sp. 2, Gigaspora sp., G. microcarpum, ont produit par contre très peu de spores avec des densités variant entre 10 et 30 spores par $100 \mathrm{ml}$ de sol. 


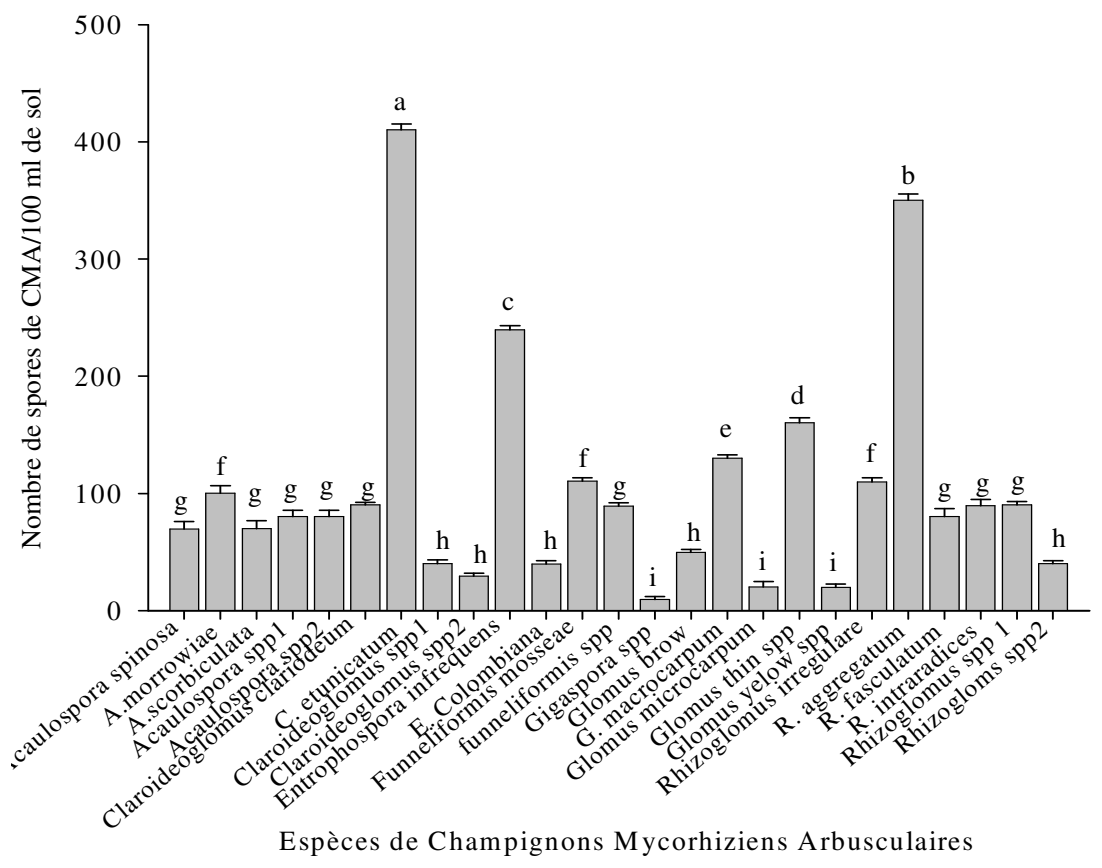

Figure 3. Densité de spores de CMA (en nombre de spores par $100 \mathrm{ml}$ de sol) extraits des échantillons de sol des systèmes de riziculture de bas-fonds après piégeage en serre sur le sorgho.

Les données sont cumulées pour les cinq zones agroécologiques. Les différences significatives sont indiquées par les lettres différentes (test de Student-Newman-Keuls au seuil de 5\%).

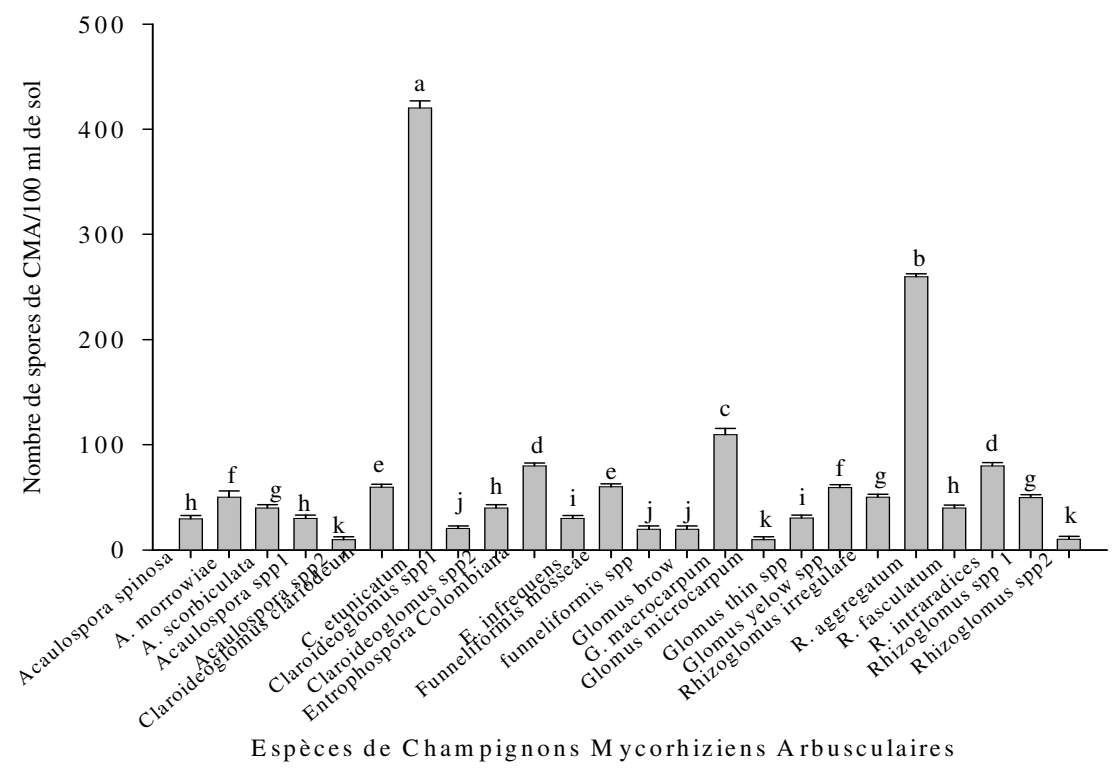

Figure 4. Densité de spores de CMA (en nombre de spores par $100 \mathrm{ml}$ de sol) extraits des échantillons de sol des systèmes de riziculture de bas-fonds après piégeage en serre sur le riz.

Les données sont cumulées pour les cinq zones agroécologiques. Les différences significatives sont indiquées par les lettres différentes (test de Student-Newman-Keuls au seuil de 5\%). 
Sur le riz par contre les densités ont été plus faibles dans la majorité des pots (Figure 4). A l'exception de $C$. etunicatum, $G$. macrocarpum et $R$. aggregatum qui ont donné des densités supérieures à 100 spores avec un maximum de $420,00 \pm 7,07$ spores pour $C$. etunicatum, suivie par $R$. aggregatum $(259,79 \pm 2,85$ spores $/ 100 \mathrm{ml}$ de sol) et $G$. macrocarpum $(109,75 \pm 5,56$ spores/ 100 $\mathrm{ml}$ de sol), la majorité des CMA ont donné des densités variant entre 10 et 90 spores pour $100 \mathrm{ml}$ de sol (Figure 4). Des espèces comme $A$. scorbiculata, C. clariodeum, Claroideoglomus sp. 2, E. colombiana, F. mosseae, Glomus yelow sp., $R$. irregulare, $R$. fasculatum, $R$. intraradices, Rhizoglomus sp. 1 , ont montré des niveaux de sporulation variant en moyenne entre 40 et 80 spores pour $100 \mathrm{ml}$ de sol. Des niveaux de sporulation plus faibles avec un maximum de 30 spores par $100 \mathrm{ml}$ de sol, ont été obtenus avec Acaulospora sp. 1, Acaulospora sp. 2, Claroideoglomus sp. 1, E. infrequens, Funneliformis sp., Glomus brow, $R$. fasculatum, Rhizoglomus sp. 2, G. microcarpum, Glomus thin sp., Glomus brow ont montré des niveaux faibles de sporulation (Figure 4). Les espèces de CMA provenant des systèmes de riziculture de plateau ont montré les niveaux de sporulation les plus faibles (Figures $5 \& 6$ ). Sur le sorgho les espèces les plus sporulantes dans le système de riz des plateaux sont Acaulospora morrowiae, Acaulospora sp. 2, Entrophospora infrequens, Rhizoglomus sp. 2 et Rhizoglomus aggregatum, avec respectivement $50 \pm$ 5,$40 ; 59,75 \pm 3,96 ; 39,75 \pm 2,06 ; 49,5 \pm 3,33$ et $49,75 \pm 1,55$ spores par $100 \mathrm{ml}$ de sol. Les autres ont montré des niveaux de densités de spores variant entre 10 et 20 spores par $100 \mathrm{ml}$ de sol (Figure 5).

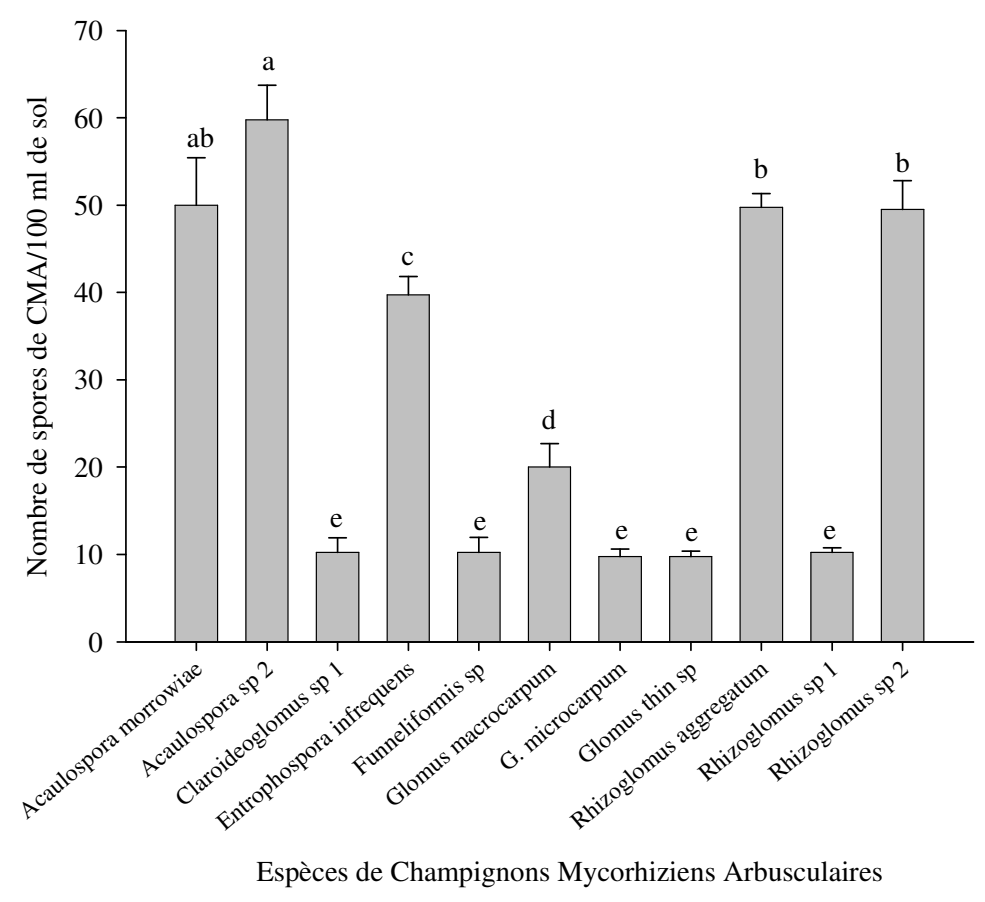

Figure 5. Densité de spores de CMA (en nombre de spores par $100 \mathrm{ml}$ de sol) extraits des échantillons de sol des systèmes de riziculture de riz de plateau après piégeage en serre sur le sorgho.

Les données sont cumulées pour les cinq zones agroécologiques. Les différences significatives sont indiquées par les lettres différentes (test de Student-Newman-Keuls au seuil de 5\%).

Les niveaux de sporulation sont encore plus faible sur le riz avec Entrophospora colombiana et $R$. agregatum représentant les deux espèces les plus sporulantes avec des densités respectives de $31,25 \pm 1,49$ et 29,5 $\pm 2,25$ spores par $100 \mathrm{ml}$ de sol. Ils sont suivis par Rhizoglomus sp. 2, G. microcarpum et Acaulospora sp.
1 avec respectivement $20,00 \pm 1,22 ; 19,75 \pm 2,32$ et $19,75 \pm 2,06$ spores par $100 \mathrm{ml}$ de sol, les reste a montré des niveaux de sporulation très faibles ne dépassant pas les 10 spores par $100 \mathrm{ml}$ de sol (Figure $6)$. 


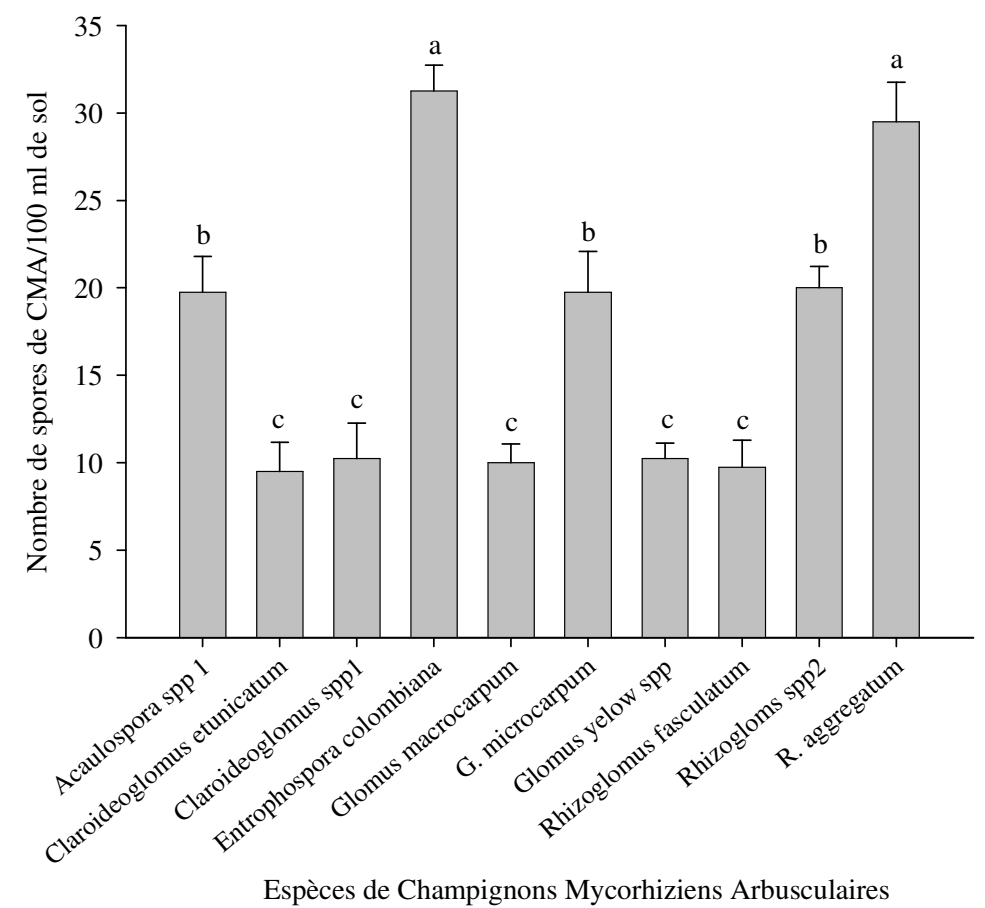

Figure 6. Densité de spores de CMA (en nombre de spores par $100 \mathrm{ml}$ de sol) extraits des échantillons de sol des systèmes de riziculture de riz de plateau après piégeage en serre sur le riz.

Les données sont cumulées pour les cinq zones agroécologiques. Les différences significatives sont indiquées par les lettres différentes (test de Student-Newman-Keuls au seuil de 5\%).

Sur les échantillons des sols inondés, la propagation des CMA était plus forte sur le sorgho que sur le riz, avec 19 espèces de CMA sporulées contre seulement 4 sur le riz (Figures $7 \& 8$ ). Les densités de sporulation sur le sorgho ont varié entre $9,75 \pm 1,25$ (Rhizoglomus sp. 1) et $149,5 \pm 4,09$ (C. etunicatum) spores par 100 $\mathrm{ml}$ de sol. A la fin des douze mois de piégeage les quatre espèces de CMA extraits sur le riz $(R$. intraradices, C. etunicatum, Claroideoglomus sp. 2 et $E$. infrequens) ont sporulé à des densités faibles variant entre 39,50 $\pm 3,07$ ( $R$. intraradices) et 70,00 $\pm 4,01$ (C. etunicatum) (Figure 8$)$. Les mêmes espèces sur le sorgho ont produit entre $100(R$. irregulare, $R$. aggregatum et $A$. scorbiculata) et 149,50 $\pm 4,09$ spores par $100 \mathrm{ml}$ de sol pour $C$. etunicatum (Figure 7). 


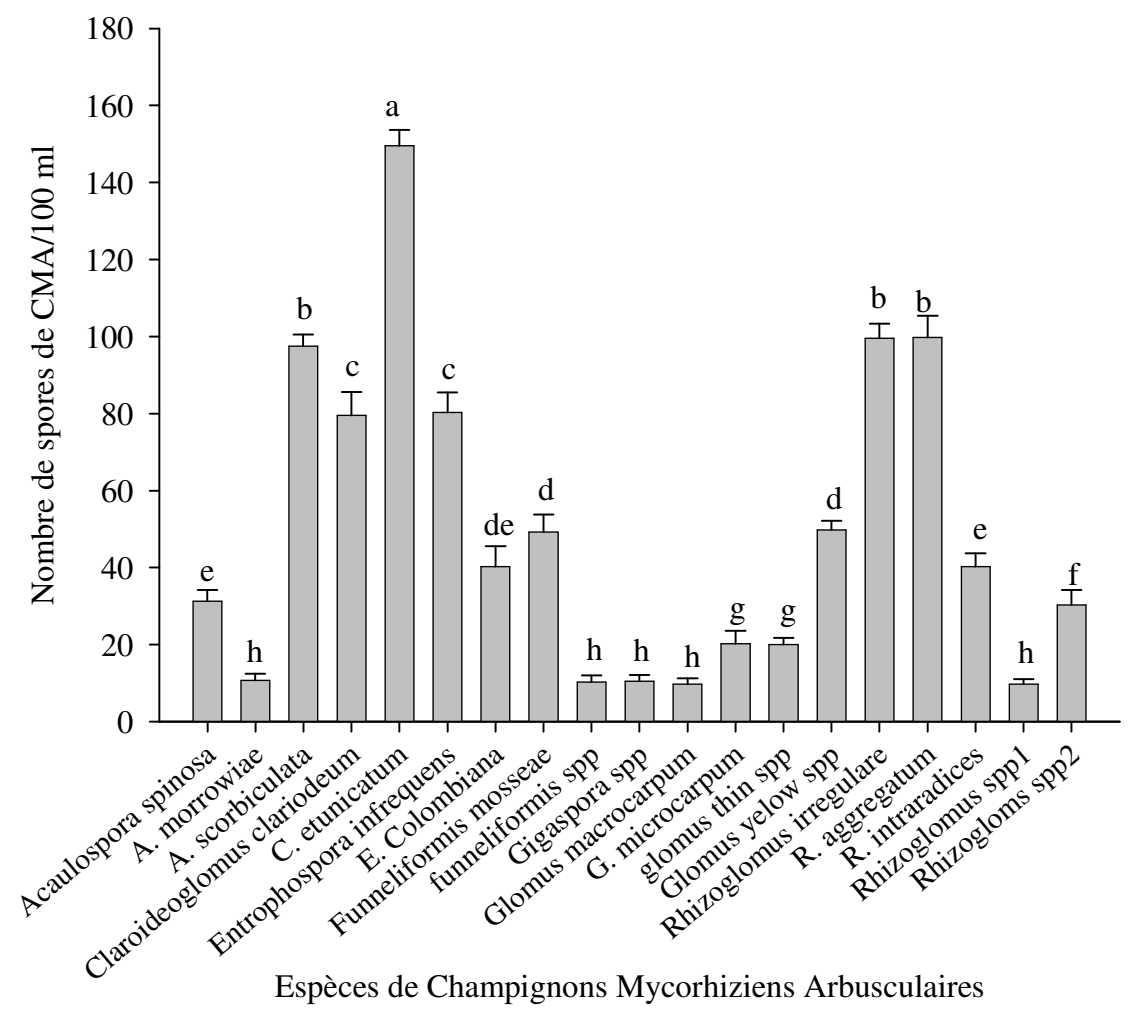

Figure 7. Densité de spores de CMA (en nombre de spores par $100 \mathrm{ml}$ de sol) extraits des échantillons de sol des systèmes de riziculture de sol inondé après piégeage en serre sur le sorgho.

Les données sont cumulées pour les cinq zones agroécologiques. Les différences significatives sont indiquées par les lettres différentes (test de Student-Newman-Keuls au seuil de 5\%). 


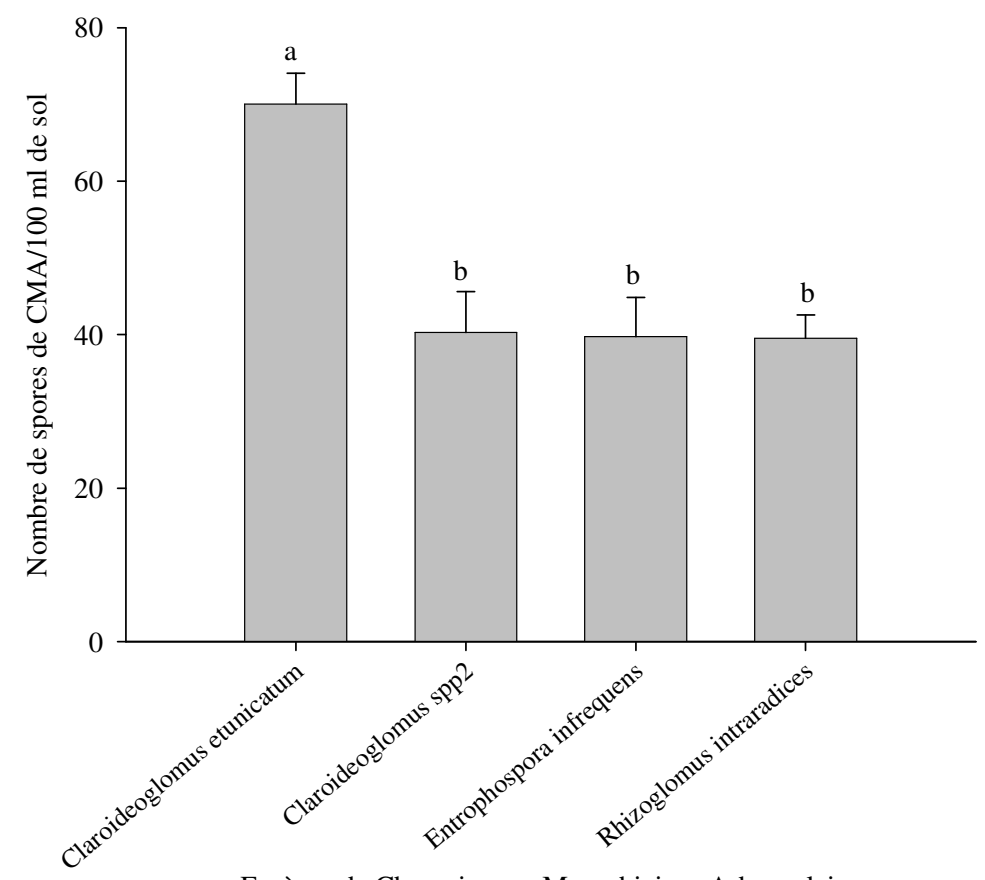

Espèces de Champignons Mycorhiziens Arbusculaires

Figure 8. Densité de spores de CMA (en nombre de spores par $100 \mathrm{ml}$ de sol) extraits des échantillons de sol des systèmes de riziculture de sol inondé après piégeage en serre sur le riz.

Les données sont cumulées pour les cinq zones agroécologiques. Les différences significatives sont indiquées par les lettres différentes (test de Student-Newman-Keuls au seuil de 5\%).

\section{DISCUSSION}

La symbiose Mycorhizienne Arbusculaire se réfère à la plus grande association mutualiste entre $90 \%$ des plantes terrestres et aquatiques examinées dans le monde et les champignons biotrophiques obligatoires appartenant à l'ordre des Glomeromycota (Schüßler, 2001; Smith et Read, 2008). Ces champignons, appelés les champignons mycorhiziens arbusculaires (CMA) représentent un groupe abondant et fonctionnellement important de microorganismes du sol, qui forment des associations symbiotiques avec leurs hôtes (Jefwa et al., 2010). Ils jouent un rôle très important dans la biologie et la chimie du sol (Smith et Read, 2008). Les mycorhizes représentent un atout pour l'agriculture, de par leurs associations (Nadeem et al., , 2014; Zhang et al., 2017) avec leurs hôtes. Les hôtes bénéficient plus souvent d'un accès accru aux nutriments, l'amélioration de la croissance et le rendement (Pozo et al., 2010; Maiti, 2011). En outre, ils fournissent une meilleure protection contre un certain nombre de ravageurs et de maladies par une induction de la résistance locale et systémique (Amel et al., 2010; Bücking et Kafle, 2015) et l'expression des gènes végétaux liés à la résistance ou des effets nématicides directs (Elsen et al., 2008). En Afrique, les CMA ont été identifiés sur plusieurs cultures avec une bonne diversité dans différentes zones agro écologiques (Tchabi et al., 2008 ; Ndoye et al., 2016; Tchabi et al., 2016 ; Aguegue et al., 2017). Au Togo, cette étude est une première et vise à établir la biodiversité des CMA associés au riz dans différentes zones de production en vue d'explorer leur potentiel sur les rendements et la protection de la culture contre les maladies et ravageurs.

Les résultats ont montré une grande diversité de CMA associés au riz avec 25 espèces appartenant à 7 genres différents. Ce résultat concorde avec les travaux de Tchabi et al.(2008) qui a rapporté 27 espèces de CMA appartenant à 7 genres associés à l'igname au 
Bénin. La diversité des CMA obtenue dans la présente étude reflète par ailleurs les résultats d'études menées dans d'autres régions tropicales, comme en Inde (Muthukumar et Udaiyan, 2000), en Amérique centrale (Husband et al., 2002) et en Afrique de l'Est (Mathimaran et al., 2007). Malgré une gestion souvent intense par l'homme, les plantes cultivées sont presque toujours colonisées par les CMA dans les écosystèmes agricoles. Cependant, la composition des communautés de CMA et l'abondance de l'inoculum fongique varient d'un site à l'autre et, en général, la colonisation mycorhizienne des plantes cultivées est limitée par la disponibilité d'inoculum fongique dans les sols agricoles (Lekberg et Koide, 2005). Les pratiques agricoles telles que la fertilisation et le travail du sol tendent à réduire l'abondance des CMA et à modifier la composition de la communauté (Egerton-Warburton et al., 2007 ; Alguacil et al., 2008). De même, la rotation des cultures peut perturber le développement d'associations cultures-CMA à long terme, et l'ordre de rotation des cultures affecte la composition de la communauté des CMA (Tchabi et al., 2008). L'étude comparative de la sporulation (densité de spores) dans le piégeage des CMA montre que le sorgho donne de meilleur rendement comparé au riz. Ceci corrobore les résultats des études antérieures qui montrent que le sorgho serait un excellent hôte dans le piégeage des CMA (Friberg, 2001; Tchabi et al., 2008).

A l'exception du genre Rhizoglomus, la diversité élevée des espèces du genre Glomus et de Acaulospora, confirme les résultats des travaux antérieurs d'autres régions en général et en Afrique de l'Ouest en particulier (Tchabi et al., 2008 ; Tchabi et al., 2009; Bansal et al., 2012; Singh et Adholeya, 2013). Cette différence s'explique par le fait que le genre Rhizoglomus est un nouveau genre proposé en 2015 avec comme espèce type un membre du genre Glomus : Glomus intraradices (Sieverding et al., 2015). Au Togo, le riz est cultivé principalement dans les basfonds, où la production continue sans interruption peut entraîner une déficience d'éléments minéraux nécessaires à un meilleur rendement, ou à une augmentation de la densité des ravageurs. Fort heureusement, c'est dans ces milieux que la diversité des CMA a été la plus élevée avec les 25 espèces répertoriées.

II faut toutefois noter que les données présentées ici peuvent encore représenter une sous-estimation, car il est probable que toutes les espèces de CMA n'aient pas été retrouvées au moment de l'identification et seulement une infime proportion de la situation réelle de la diversité des mycorhizes dans les systèmes de riziculture ait été détectée dans la présente étude. En effet sur 150 échantillons prélevés dans les différentes rizières des cinq zones agroécologiques du pays seuls 30 échantillons ont pu être effectivement examinés. Les autres échantillons ayant été soit dégradés ou que la propagation des CMA ayant été infructueuse sur les cultures pièges utilisées. Par ailleurs, l'outil morphologique d'identification utilisé pourrait aussi être une limite. En effet en utilisant des outils morphologiques d'identification comme c'est dans le cas de la présente étude, la richesse en CMA peut également être sous-estimée car certaines espèces n'auraient pas pu sporuler durant la période d'échantillonnage (Bever et al., 2001) ou que les spores isolées du champ sont dégradées et ne conviennent pas à l'identification (Rodriguez et al., 2005). De nouvelles données provenant d'études en cours indiquent que le moment de l'échantillonnage dans la présente étude, vers la fin de la saison humide, n'était pas optimal et expliquait au moins en partie pourquoi la propagation des CMA était largement infructueuse.

Le genre Gigaspora a été endémique aux Plaines du nord et aux Plaines côtières du sud uniquement dans les pots ensemencés au sorgho. La diversité spécifique et l'abondance des champignons MA dans le sol sont influencés par l'écologie du milieu et le mode d'occupation des sols mais aussi par le type de plantes pièges. Suivant les systèmes de culture du riz, la richesse spécifique des CMA dans les basfonds a été la plus importante. Tous les vingt-cinq spécimens ont été dénombrés dans ces milieux alors que les zones inondées et les plateaux ne regorgeaient respectivement que 16 et 20 espèces. Cette richesse spécifique dans les basfond serait la conséquence d'une intensification de la culture du riz dans cet écosystème.

Suivant le système de culture et la plante piège, les densités de spores ont été très variables. La densité de spores a été très élevée avec les plants de sorgho inoculé avec les sols de basfond. Huit espèces ont une densité en spore variant entre 100 et 410,25 \pm 4,91 spores par $100 \mathrm{ml}$ de sol alors qu'avec les pots ensemencés de riz, C. etunicatum, G. macrocarpum et $R$. aggregatum ont donné des densités supérieures à 100 spores avec un maximum de $420,00 \pm 7,07$ spores pour $C$. etunicatum. De par les interactions positives avec les plantes pour l'absorption des éléments nutritifs (Clark et Zeto, 2000 ; Cardoso et al., 2006) et même la défense des plantes contre les bioagresseurs (Hause et al., 2007 ; Van Wees et al., 2008), les CMA sont 
davantage très utiles pour les régions où les sols sont très dégradés. Leur large distribution géographique se caractérise par une importante variabilité décelable au sein de la biologie de leur population, de la spécificité écologique et de l'activité symbiotique. Bien que les CAM soient présents dans les zones humides de production de riz (Watanarojanaporn et al., 2013; Wang et al., 2015), leur taux de colonisation diminue avec le développement accru de l'aérenchyme dans les

\section{CONCLUSION}

Cette étude qui est la première du genre au Togo, a montré une grande diversité des CMA dans les différentes zones agroécologiques de culture du riz au

\section{RÉFÉRENCES}

Adjonou K, Djiwa O, Kombate Y, Kokutse AD et Kokou $K, 2010$. Etude de la dynamique spatiale et structure des forêts denses sèches reliques du Togo: implications pour une gestion durable des aires protégées. International Journal of Biological and Chemical Sciences, 4: 168-183.

Aguegue RM, Noumavo PA, Gustave, Dagbenonbakin $D$ et Baba-Moussa L, 2017. Arbuscular Mycorrhizal Fertilization of Corn (Zea mays L.) Cultivated on Ferrous Soil in Southern Benin. Journal of Agricultural Studies, 5: 99-115.

Alguacil MM, Lumini E, Roldán A, Salinas-García JR, Bonfante $\mathrm{P}$, Bianciotto $\mathrm{V}, 2008$. The impact of tillage practices on arbuscular mycorrhizal fungal diversity in subtropical crops. Ecological Applications, 18: 527-536.

Amel A, Soad H, Ahmed M et Ismail AA, 2010. Activation of tomato plant defense response against fusarium wilt disease using Trichoderma harzianum and salicylic acid under greenhouse conditions. Research Journal of Agriculture \& Biological Sciences, 6 : 328-338.

Apple ME, 2010. Aspects of mycorrhizae in desert plants. In: Rama- wat KG (ed) Desert plants. Springer, Berlin, pp 121-134.

Bansal M, Kukreja K et Dudeja SS, 2012. Diversity of Arbuscular mycorrhizal fungi, prevalent in rhizosphere of different crops grown in the university farm. African Journal of Microbiology Research, 6: 4557-4566.

Bárzana G, Aroca R, Paz JA, Chaumont F, MartinezBallest MC et Carvajal M, 2012. Arbuscular mycorrhizal symbiosis increases relative apoplastic water flow in roots of the host plant racines (Vallino et al., 2014). Ainsi la faible colonisation mycorhizienne dans les systèmes de riz inondé trouve bien sa justification dans la présente étude. Par ailleurs, le potentiel des mycorhizes à favoriser l'accumulation par les plantes de l'eau dans les milieux défavorisés en eau (Apple, 2010; Bárzana et al., 2012) peut bien expliquer la faible diversité et propagation des CMA provenant du système du riz inondé où le besoin en eau pour la plante est réduit.

Togo et requière plus d'investigations afin d'établir leurs rôles sur le rendement et la lutte contre les maladies et ravageurs.

under both well-watered and drought stress conditions. Annals of Botany, 109: 1009-1017.

Bever JD, Schultz PA, Pringle A et Morton JB, 2001. Arbuscular mycorrhizal fungi: more diverse than meets the eye and the ecological tale of why. Bioscience, 51: 923-931

Brundrett M, Melville L et Peterson L, 1994. Practical methods in mycorrhiza research: based on a workshop organized in conjunction with the ninth North American Conference on Mycorrhizae, University of Guelph, Guelph, Ontario. Mycologue Publications, c1994. 161 $p$.

Bücking $H$ et Kafle $A, 2015$. Role of arbuscular mycorrhizal fungi in the nitrogen uptake of plants: current knowledge and research gaps. Agronomy, 5: 587-612.

Cardoso IM et Kuyper TW, 2006. Mycorrhizas and tropical soil fertility. Agriculture, Ecosystems and Environment, 116: 72-84.

Cardoso IM, Boddington C, Janssen BH, Oenema $\mathrm{O}$ et Kuyper TW, 2006. Differential access to phosphorus pools of an Oxisol by mycorrhizal and non-mycorrhizal maize. Communications in Soil Science and Plant Analysis, 37: 1-15.

Clark RB et Zeto SK, 2000. Mineral acquisition by arbuscular mycorrhizal plants. Journal of Plant Nutrition, 23: 867-902.

Defoer $T$ et Scoones I, 2001. Participatory approaches to integrated soil fertility management. In: Scoones I (ed) Dynamics and diversity: soil fertility management and farming livelihoods in Africa: case studies from Ethiopia, Mali and Zimbabwe. Earthscan Publications Ltd, London, UK, pp 64-67. 
Egerton-Warburton LM, Querejeta Jl et, Allen MF. 2007. Common mycorrhizal networks provide a potential pathway for the transfer of hydraulically lifted water between plants. Journal of Experimental Botany 58: 14731483.

Elsen A, Gervacio D, Swennen R et De Waele D, 2008. AMF-induced biocontrol against plant parasitic nematodes in Musa sp.: a systemic effect. Mycorrhiza, 18: 251-256.

Friberg S, 2001. Distribution and diversity of arbuscular mycorrhizal fungi in traditional agriculture on the Niger inland delta, Mali, West Africa. CBM s Skriftserie, 3: 53-80.

Fuehrer M, 2011. Sustainable farming practices key to combating climate change. http://www.dw.de/dw/article/0,14880332,000ht $\underline{\mathrm{ml}}$

Gai JP, Cai XB, Feng G, Christie P, Li XL, 2006. Arbuscular mycorrhizal fungi associated with sedges on the Tibetan plateau. Mycorrhiza 16: 151-157.

Hause B, Mrosk C, Isayenkov S et Strack D, 2007. Jasmonates in arbuscular mycorrhizal interactions. Phytochemistry, 68: 101-110.

Husband R, Allen HJ, Peter W et Young JPW, 2002. Temporal variation in the arbuscular mycorrhizal communities colonising seedlings in a tropical forest. FEMS Microbiology Ecology, 42:131-136.

IRRI, 2011. Rice and climate change. http://irri.org news-events/hot-topics/rice-and-climate change.

Jansa J, Mozafar A, Anken T, Ruh R, Sanders IR et Fossard E, 2002. Diversity and structure of AMF communities as affected by tillage in a temperate soil. Mycorrhiza, 12: 225-234.

Jefwa J, Vanlauwe B, Coyne D, Van Asten P, Gaidashova S, Mwashasha M et Elsen A, 2010. Benefits and Potential Use of Arbuscular Mycorrhizal Fungi (AMF) in Banana and Plantain (Musa spp.) Systems in Africa. Proc. IC on Banana \& Plantain in Africa Eds: T. Dubois et al. Acta Horticulturae 879 : 479-486.

Johnson NC, Copeland PJ, Crookston RK et Pfleger FL, 1992. Mycorrhizae-possible explanation for yield decline with continuous corn and soybean. Agronomy journal, 84: 387-390

Klauberg Filho O, Siqueira JO, Moreira FMS, 2002. Vesicular arbuscular mycorrhizae fungi in soils polluted with heavy metals. Revista Brasileira de Ciência do Solo, 26: 125-134.

Lamouroux M, 1960. Carte pédologique du Togo. ORSTOM, Lomé-Togo.

Lekberg Y, Koide RT, Rohr JR, Aldrich-Wolfe L et Morton JB, 2007. Role of niche restrictions and dispersal in the composition of arbuscular mycorrhizal fungal communities. Journal of Ecology, 95: 95-105.

Lekberg Y et Koide RT, 2005. Is Plant Performance Limited by Abundance of Arbuscular Mycorrhizal Fungi? A Meta-Analysis of Studies Published between 1988 and 2003. New Phytologist, 168: 189-204.

Lovelock CE et Ewel JJ, 2005. Links between tree species, symbiotic fungal diversity and ecosystem functioning in simplified tropical ecosystems. New Phytologist, 167: 219-228

Lovera M et Cuenca G, 2007. Diversity of arbuscular mycorrhizal fungi (AMF) and mycorrhizal potential of the soil from a natural and a disturbed savannah from La Gran Sabana, Venezuela. Interciencia, 32: 108-114.

Maiti D, 2011. Improving activity of native Arbuscular Mycorrhizal Fungi (AMF) for mycorrhizal benefits in agriculture: Status and Prospect. Journal of Biofertilizers \& Biopesticides, S1:001. doi:10.4172/2155-6202.S1-001

Mathimaran N, Ruh R, Jama B, Verchot L, Frossard E, et Jansa J, 2007. Impact of agricultural management on arbuscular mycorrhizal fungal communities in Kenyan Ferralsol. Agriculture, Ecosystems and Environment, 119: 22-32

Melloni R, Siqueira JO et Moreira FMS, 2003. Arbuscular mycorrhizal fungi in soils of bauxite mining area under rehabilitation. PAB, 38: 267276.

Muthukumar $\mathrm{T}$ et Udaiyan $\mathrm{K}, 2000$. Arbuscular mycorrhizas of plants growing in the Western Ghats region, Southern India. Mycorrhiza 9: 297-313.

Nadeem SM, Ahmad M, Zahir ZA, Javaid A et Ashraf $M, 2014$. The role of mycorrhizae and plant growth promoting rhizobacteria (PGPR) in improving crop productivity under stressful environments. Biotechnology Advances, 32: 429-448.

Ndoye F, Diedhiou AG, Gueye M, Fall D, Barnaud A, Sy MO, Noba K, Diouf D et Kane A, 2016. Réponse du fonio blanc (Digitaria exilis Stapf) à l'inoculation avec des champignons 
mycorhiziens à arbuscules en conditions semicontrôlées. Journal of Applied Biosciences, 103: 9784-9799.

Oehl F, Sieverding E, Ineichen K, Mäder P, Boller T, Wiemken A, 2003. Impact of land use intensity on the species diversity of arbuscular mycorrhizal fungi in agroecosystems of Central Europe. Applied and Environmental Microbiology 69: 2816-2824.

Oehl F, Sieverding E, Ineichen K, Ris E-A, Boller T, et Wiemken A, 2005. Community structure of arbuscular mycorrhizal fungi at different soil depths in extensively and intensively managed agroecosystems. New Phytologist, 165: 27328.3

Oehl F, Sieverding E, Mäder $P$, Dubois $D$, Ineichen $K$, Boller T et Wiemken A, 2004. Impact of longterm conventional and organic farming on the diversity of arbuscular mycorrhizal fungi. Oecologia, 138: 574-583.

Pozo MJ, Jung SC, Lopez-Raez JA et Acon-Aguilar C, 2010. Impact of arbuscular Mycorrhizal symbiosis on plant response to biotic stress. The role of plant defense mechanisms. In Koltai, H. (Eds.), Arbuscular Mycorrhizas: Physiology and Function, pp. 193-208.

Redecker D, 2000. Specific PCR primers to identify arbuscular mycorrhizal fungi within colonized roots. Mycorrhiza 10: 73-80.

Rillig MC, Ramsey PW, Morris S et Paul EA, 2003. Glomalin, an arbuscular-mycorrhizal fungal soil protein, responds to land-use change. Plant and Soil, 253: 293-299.

Rodriguez A, Clapp JP, Robinson L, Dodd JC, 2005. Studies on the diversity of the distinct phylogenetic lineage encompassing Glomus claroideum and Glomus etunicatum. Mycorrhiza, 15: 33-46.

Schenck NC et Pérez $Y, 1990$. Manual for the identification of VA mycorrhizal fungi. Synergistic-Publications, Gainesville, Florida.

Schüßler A, Schwarzott D et Walker C, 2001. A new fungal phylum, the Glomeromycota: phylogeny and evolution. Mycological Research, 105: 1413-1421.

Sieverding E, da Silva GA, Berndt R et Oehl, F, 2015. Rhizoglomus, a new genus of the Glomeraceae. Mycotaxon 129: 373-386.

Singh R, Adholeya A, 2013. Diversity of AM (Arbuscular mycorrhizal) Fungi in Wheat Agro-climatic
Regions of India. Virol Mycol 2:116. doi:10.4172/2161-0517.1000116

Siqueira JO et Saggin-Júnior OJ, 2001. Dependency of arbuscular mycorrhizal fungi and responsiveness of some Brazilian native woody species. Mycorrhiza, 11: 245-255.

Smith SE et Read D, 2008. Mycorrhizal symbiosis. (3rd ed.). San Diego: Academic Press, pp. 117-44.

Tchabi A, Coyne D, Hountondji F, Lawouin L, Wiemken A et Oehl F, 2008. Arbuscular mycorrhizal fungal communities in subSaharan Savannas of Benin, West Africa, as affected by agricultural land use intensity and ecological zone. Mycorrhiza, 18: 181-195.

Tchabi A, Hountondji F, Ogunsola B, Lawouin L, Coyne $D$, Wiemken A et Oehl F, 2016. Effect of two species of arbuscular mycorrhizal fungi inoculation on development of micropropagated yam plantlets and suppression of Scutellonema bradys (Tylenchideae). Journal of Entomology and Nematology,8: 1-10.

Tchabi A, Burger S, Coyne D, Hountondji F, Lawouin L, Wiemken A, Oehl F, 2009. Promiscuous arbuscular mycorrhizal symbiosis of yam (Dioscorea spp.), a key staple crop in West Africa. Mycorrhiza, 19: 375-392.

Vallino M, Fiorilli $V$ et Bonfante $P, 2014$. Rice flooding negatively impacts root branching and arbuscular mycorrhizal colonization, but not fungal viability. Plant Cell Environ, 37: 557-72.

Van Wees SCM, Van der Ent, S et Pieterse CMJ, 2008. Plant immune responses triggered by beneficial microbes. Current Opinion in Plant Biology, 11: 443-448.

Wang Y, Li T, Li Y, Bjorn LO, Rosendah S, Olsson PA, Li S et Fu X, 2015. Community dynamics of arbuscular mycorrhizal fungi in high-input and intensively irrigated rice cultivation systems. Applied and Environmental Microbiology, 81: 29-58.

Watanarojanaporn $\mathrm{N}$, Boonkerd $\mathrm{N}$, Tittabutr $\mathrm{P}$, Longtonglang A, Young JP et Teaumroong N, 2013. Effect of rice cultivation systems on indige- nous arbuscular mycorrhizal fungal community structure. Microbes and Environments, 28:316-24.

Wu B, Hogetsu T, Isobe K et Ishii R, 2007. Community structure of arbuscular mycorrhizal fungi in a primary successional volcanic desert on the southeast slope of Mount Fuji. Mycorrhiza, 17: 495-506. 
Yan X., Yagi K., Akiyama H., Akimoto H. 2005. Statistical analysis of the major variables controlling methane emission from rice fields. Global Change Biology, 7: 1131-1141.
Zhang YC, Wang P, Wu QH, Zou YN, Bao Q et Wu QS, 2017. Arbuscular mycorrhizas improve plant growth and soil structure in trifoliate orange under salt stress. Archives of Agronomy and Soil Science, 63 : 491-500. 